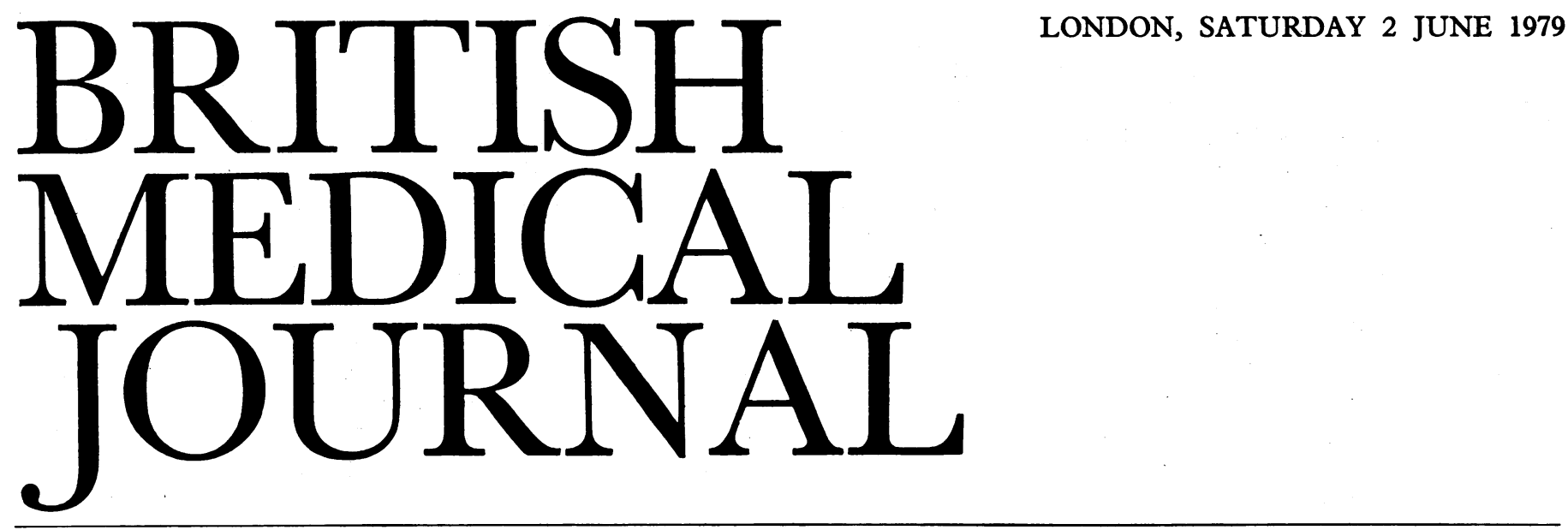

The first successful orthotopic liver transplantation in man was carried out by Starzl ${ }^{1}$ in 1963. Since then over 300 such operations have been performed, mostly in just two centres. ${ }^{2} 3$ In Britain 83 operations have been done in the joint programme between Addenbrooke's Hospital at Cambridge and King's College Hospital in London started in 1968, and in the USA Starzl's series in Denver now amounts to 140 patients.

Progress has been made on several fronts. One of the initial technical difficulties which accounted for poor survival was breakdown of the biliary anastomosis, resulting in leakage of bile or obstruction, and inevitably followed by cholangitis and septicaemia. The introduction by Calne of a gall bladder conduit procedure, ${ }^{4}$ in which the donor gall bladder is positioned between the common bile ducts of the donor and recipient and is splinted by a $\mathrm{T}$-tube, appreciably reduced these complications. Starzl prefers the end-to-end common bile duct anastomosis over an indwelling T-tube. Hypothermic techniques for preserving the liver ${ }^{5}$ have made it possible to transport donor livers from distant hospitals, so increasing the numbers of potential donor livers that can be maintained in good condition for up to 10 hours before implantation.

Fortunately, the liver appears to be immunologically privileged, and in both the British and the American series uncontrollable rejection has accounted for fewer than $10 \%$ of deaths. Though acute rejection episodes are common in the first few weeks after operation, they can be controlled easily by increasing the dose of immunosuppressive drugs.

Most patients in the British series have been adults, with only seven of the 83 under 18 years old. In contrast, $60 \%$ of the Denver series have been children. ${ }^{6}$ Starzl believes that children are the best recipients for liver transplants, and in adults he recommends an upper age limit of 45 years for transplantation. Nevertheless, the Cambridge/King's group have achieved good results in patients in their $50 \mathrm{~s}$.

Liver transplantation has been tried for practically every type of severe irreversible liver damage for which no other treatment is possible. End-stage cirrhosis and primary malignancy of the liver are the two main current indications. Unfortunately, many patients have been referred at a terminal stage of their illness, and in part this has contributed to poor survival figures. Judgment of the optimum time for transplantation is especially difficult in cirrhosis, where both the clinical course of the disease and life expectancy are so variable: a sudden and unpredictable deterioration may occur, for example, after variceal haemorrhage or infection. Despite some advances in the development of liver support systems for fulminant hepatic failure, ${ }^{7}$ these cannot maintain patients awaiting liver transplantation, as is possible in renal grafting.

In many ways patients with non-resectable primary tumours of the liver are the most suitable candidates for transplantation, since they are often young and have a poor prognosis. Only a few of these patients finally prove suitable for transplantation, however, since metastases are often already present by the time the lesion is diagnosed. In the Cambridge/King's series ${ }^{8}$ six of the 24 patients grafted for primary hepatocellular carcinoma lived for over one year and two of these remain alive and well after four and three years. The longest-surviving patient before this lived for five and a quarter years with no evidence of tumour recurrence. Worthwhile palliation was seen in a further seven patients, who were discharged home for periods up to 11 months, though overall the tumour recurred in two-thirds. With carcinoma of the hepatic ducts (Klatskin tumour $)^{9}$ tumour recurrence has been rapid in almost all cases, and patients with this condition should not be considered for transplantation.

Of the patients with cirrhosis, the most successful results have been in those with primary biliary cirrhosis. In the Cambridge/King's series four of the nine patients in this group are alive and well after one to two years. Another patient with primary sclerosing cholangitis remains well after two years, and one patient with secondary biliary cirrhosis survived one and a half years before death from chronic rejection. Two other long-term survivors include one with cryptogenic cirrhosis and one with chronic active hepatitis and advanced cirrhosis. Of the successful outcomes in transplantation for cirrhosis, the common feature has been the maintenance of adequate hepatic cell function before surgery. In contrast, among the patients who had severe hepatic decompensation with hypotension, bleeding, renal failure, or infection at the time of grafting, death was common within six weeks of operation; mostly owing to haemorrhage or sepsis.

Budd-Chiari syndrome carries a poor prognosis, though Orloff ${ }^{10}$ has reported successful treatment using early side-toside portacaval shunts. Putnam ${ }^{11}$ has described one long-term survivor after transplantation, and in the Cambridge/King's series one of three patients grafted for this condition remains alive and well after two years. Hepatitis $B$ infection has been considered a contraindication to liver transplantation because 
of reinfection of the graft. ${ }^{12}$ Nevertheless, the British team has transplanted four patients positive for hepatitis $B$ virus using large doses of specific anti-HBs immunoglobulin given during the anhepatic phase of liver grafting. All four became free of virus after surgery and remained so, including one who is still alive after three years. ${ }^{13}$

In children receiving transplants Starzl has recently reported that almost half survive at one year. ${ }^{14}$ The main indication has been biliary atresia, and one such patient is the world's longest survivor of liver transplantation after nine years. The second indication in children has been inborn errors of metabolism, with reports of successful long-term survival in Wilson's disease, ${ }^{6}$ alpha ${ }_{1}$-antitrypsin deficiency, ${ }^{15}$ tyrosinaemia, ${ }^{6}$ and Niemann-Pick disease. ${ }^{16}$ In these cases the primary metabolic defect in the liver has been corrected successfully by transplantation.

The results of liver transplantation show that prolonged survival is possible, and the success rate has improved as a result of advances in surgical techniques. Further improvement in survival will come from a more critical selection of patients -and from referral of patients earlier.

1 Starzl, T E, et al, Surgery, Gynecology, and Obstetrics, 1963, 117, 659.

2 Calne, R Y, and Williams, R, British Medical fournal, 1977, 1, 471.

3 Starzl, T E, et al, Surgery, Gynecology, and Obstetrics, 1976, 142, 487.

4 Calne, R Y, Annals of Surgery, 1977, 184, 605.

5 Wall, W J, et al, Transplantation, 1977, 23, 210.

6 Putnam, C W, et al, World fournal of Surgery, 1977, 1, 165.

7 Williams, $R$, in Progress in Liver Diseases, vol 5, ed $\mathrm{H}$ Popper and $\mathrm{F}$ Schaffner, p 418. New York, Grune and Stratton, 1976.

8 Macdougall, B R D, and Williams, R, VII International Congress of the Transplantation Society, Rome 1978, in press.

- Klatskin, G, American fcurnal of Medicine, 1965, 38, 241.

10 Orloff, M J, and Johansen, K H, Annals of Surgery, 1978, 188, 494.

${ }^{11}$ Putnam, C W, et al, fournal of the American Medical Association, 1976, 236, 1142.

12 Starzl, T E, et al, Transplantation Proceedings, 1972, 4, 759.

13 Johnson, P J, et al, British Medical fournal, 1978, 1, 216.

14 Starzl, T E, VII International Congress of the Transplantation Society, Rome 1878 , in press.

15 Putnam, C W, et al, Surgery, 1977, 81, 258.

${ }^{16}$ Daloze, P, et al, Transplantation Proceedings, 1975, 7, 607.

\section{Tuberculous paraplegia}

There is an old adage that goes "Tuberculosis changes with time and place." Freilich and Swash ${ }^{1}$ have recently shown that the pattern of tuberculous paraplegia in Britain has altered greatly owing to the arrival of Asian immigrants. Of eight patients presenting in five years at the London Hospital with paraplegia of tuberculous origin, all but one was Asian, and only three had vertebral disease.

In the minds of many clinicians paraplegia due to tuberculosis is almost always associated with ". . . that kind of palsy of the lower limbs which is frequently found to accompany a curvature of the spine, and is supposed to be caused by it," as Percivall Pott said..$^{2}$ There are, however, other causes and $\mathrm{Wadia}^{3}$ has suggested the following classification: primary tuberculous spinal radiculomyelitis, and radiculomyelitis secondary either to vertebral tuberculosis or to tuberculous basal meningitis. The term primary is perhaps unfortunate, since it is not in the strict sense a primary tuberculous lesion but rather the first clinical manifestation of tuberculosis in the central nervous system.

Whatever the cause of the paraplegia, there is an almost invariable combination of root and cord signs accounting for the local and radicular pain and the flaccid, areflexic paraparesis with distal sensory impairment and extensor plantar responses. Spinal block often occurs before paraplegia even in patients with vertebral tuberculosis. ${ }^{1}$ In Pott's paraplegia the compression may be caused by a paraspinal abscess invading the spinal cord; granulation tissue encroaching on the dura, sequestrated bone, or intervertebral disc; and, rarely, by dislocation of a vertebra. Tuberculosis of the spine affects the spinal cord in about a fifth of cases. The mid-dorsal lesion is the most common, but spinal cord compression occurs more frequently in cervicodorsal disease. Primary tuberculous spinal radiculomyelitis, which is a common cause of paraplegia in India, seems to arise as a localised arachnoiditis derived from a blood-borne tuberculous focus in the meninges.

Treatment by chemotherapy is essential, whatever the cause. Extensive trials have shown that isoniazid and aminosalicylic acid (PAS) for 18 months constitute a satisfactory regimen for tuberculous paraplegia, and that a third drug should be considered only in patients who have previously received chemotherapy for a long period or who live in areas where there is a high initial level of drug resistance. ${ }^{5}$ Recent studies have shown that short-course chemotherapy with rifampicin-containing regimens is highly effective in pulmonary tuberculosis. ${ }^{6}$ Thus nine-month, or even six-month, regimens should also be effective in skeletal tuberculosis, particularly as spinal lesions contain fewer bacilli than do pulmonary lesions ${ }^{7}$; current trials should establish whether this is so. Steroids have not been properly evaluated, but they should be used for patients with meningitis.

Paraplegia arising during active tuberculous disease may well respond to chemotherapy alone-indeed, before chemotherapy was available some two-fifths of patients recovered full function of the spinal cord after purely conservative care. ${ }^{8}$ At three of the centres-Musan, Pusan, and Bulawayo-in which the Medical Research Council Working Party on Tuberculosis of the Spine carried out its excellent studies, ${ }^{9}$ the spinal cord was affected in 43 patients. Fourteen of these had surgery. One of the 11 with paraparesis died, and there was no evidence that operation expedited recovery in the others; two of the four with paraplegia died, and in the other two the paraplegia was soon relieved. A total of 23 patients with paraparesis and five with paraplegia were treated conservatively, and all but one-who still has paraparesis after 60 months-recovered completely by 36 months. Nevertheless, some believe that patients should not lie waiting for spontaneous cure when operation can often produce functional recovery in a few days. ${ }^{10}$

As the pressure is anterior to the dura mater, decompression must be carried out from the front either anterolaterally ${ }^{11}$ or, preferably, by the Hong Kong radical resection with subsequent anterior fusion. ${ }^{912}$ Recent studies in South Africa ${ }^{13}$ have shown that the radical Hong Kong and the simple debridement operations were about equally successful in relieving compression of the spinal cord and in producing favourable results at three years. Of the five paraplegics who died, however, four were in the debridement series. As might be expected, recovery was slower in the paraplegic than in the paraparetic patients. Radical resection of the tuberculous focus with anterior spinal fusion, it must be emphasised, requires considerable skill.

Tuberculous paraplegia remains common in developing countries and doctors should be especially alert to tuberculosis as a cause of paraplegia among Asians in any community.

\footnotetext{
${ }^{1}$ Freilich, D, and Swash, M, fournal of Neurology, Neurosurgery, and Psychiatry, 1979, 42, 12.

2 Pott, P, 1779, reprinted in Medical Classics, 1936, 1 , no 4.
} 